\title{
ANATOMICAL MEASUREMENTS OF CEREBRAL ARTERIES USING DIGITAL SUBTRACTION ANGIOGRAPHY
}

\section{Nancy Husseiny Hassan, Metwally Abd El-Bary Mansor, Amal Al-Shahat Ibrahim and Ibrahim Hassan Ibrahim}

Department of Human Anatomy and Embryology, Faculty of Medicine, Zagazig University, Sharkia, Egypt

\section{Corresponding:}

Ibrahim Hassan Ibrahim

Mobile: +201006501801

Email:

ebrahimelazony5555@yahoo.com

Received:26/2/2020

Accepted: 18/3/2020

Online ISSN: 2735-3540

\begin{abstract}
:
Background: The knowledge of anatomical measurements of cerebral arteries has a great value for understanding of several neurologic disorders .

Aim of the work: To measure diameters and lengths of anterior cerebral artery (ACA), posterior cerebral artery (PCA) and middle cerebral artery (MCA) on both sides to give basis for normal Egyptian measurements of cerebral arteries using Digital Subtraction Angiography (DSA).
\end{abstract}

Subjects and Methods: Fifty healthy individuals who had normal DSA, including 33 males and 17 females aged from 20 years to 60 years were examined during this study. Chosen subjects were classified into two age groups, Group 1: that included 18 persons (between 20-39 years old). Group 2: that included 32 persons (between 40-60 years old). DSA used to measure the diameters and lengths of main cerebral arteries (ACA, MCA and PCA) at different segments .

Results: Regarding to the age of studied subjects, there was statistical significant difference between the diameters of cerebral arteries at different segments in the studied groups and the diameters of these arteries were decreased by advancing in age. There was statistical significant difference between the lengths of cerebral arteries at different segments in the studied groups and the lengths of these arteries were more in the older age group. The differences between means of lengths of cerebral arteries on the right and on the left side was statistically non-significant in all segments except that of middle cerebral artery-segment 1 (MI) which was statistically significant.

Conclusion: Establishment of Egyptian normal measurements of cerebral arteries using Digital Subtraction Angiography has a great value in interpretation of cranial angiograms as these measurements may vary in different races.

Keywords: Cerebral arteries, DSA, cerebral segments.

\section{INTRODUCTION:}

The two internal carotid arteries and the vertebrobasilar system form a ring anastomosis called circle of Willis on the base of the brain. The vessels diverge from this anastomosis passing to supply the various cerebral regions ${ }^{1}$. Intracranial arteries are involved in multiple neurologic disorders, also knowledge of anatomy of these arteries and their normal variationsis essential to define the location of neurovascular lesions ${ }^{2}$. Digital Subtraction Angiography (DSA) is a promising method for improving the results 
of cerebrovascular angiography ${ }^{3}$. There are two anterior cerebral arteries anastomose together by anterior communicating artery ${ }^{4}$. The classical azygos anterior cerebral artery was seen in the anterior median cerebral fissure of brain in $(2.7 \%)$ of persons and this artery supplied the two cerebral hemispheres through its branches 5 . The aim of the present work was to put a spot light on the anatomical Egyptian measurements of the diameters and lengths of anterior cerebral artery (ACA), posterior cerebral artery (PCA) and middle cerebral artery (MCA) on both sides by using DSA.

\section{SUBJECTS AND METHODS:}

\section{Subjects:}

Fifty healthy individuals had normal DSA, including 33 males and 17 females aged from 20 years to 60 years were examined during this study. These subjects were chosen from the interventional radiology unit, Diagnostic Radiology Department at Zagazig University Hospitals. The patients were subjected to full history taking and laboratory tests including liver function tests (LFT), kidney function tests (KFT), complete blood picture (CBP) and bleeding profile (prothrombin time (PT), partial thromboplastin time (PTT) \&International normalized ratio (INR) ). Computed Tomography (CT) of the head and base of the skull for all persons was done.

Exclusion criteria: Any positive criteria indicating a neurological pathology from the history taken or upon viewing the subject's MRI was an indicator to exclude this subject from the study protocol.

The study was reviewed and approved by IRB (Institutional Review Board), Faculty of Medicine, Zagazig University. The chosen subjects were classified into two age groups:
Group 1 (G1): included 18 persons (2039 years).

Group 2 (G2): included 32 persons (4060 years).

\section{Methods:}

DSA examinations were done using a digital angiographic unit (Siemens Artis Zee monoplane) to measure lengths and the diameters of the cerebral arteries on both sides. The projections that showed minimum overlapping of the cerebral arteries under measurement were selected for taking measurements. For identification of the segments of the cerebral arteries, landmark software was used to add a bony landmark into the images. The diameter of each cerebral artery was measured as a mean of the diameters at the beginning midpoint and end of each segment. Straight segments measured by a single line between the beginning and the end of each segment. The ACA has a tortuous course, so its length was measured in segments then were added together for calculation its total length ${ }^{4}$.

The ACA segment-1 (A1) was measured between its origin from the internal carotid artery and at its junction with the anterior communicating artery ${ }^{4}$ while the ACA segment -2 (A2) was measured from its junction with the anterior communicating artery and this segment also called post communicating part of $\mathrm{ACA}^{5}$. The MCA segment-1 (M1) was measured from the termination of the internal carotid artery and through the main stem of MCA till its bi/trifurcation ${ }^{6}$. The PCA segment-1 (P1) was measured from the basilar bifurcation to its junction with the posterior communicating artery while the PCA segment -2 (P2) was measured from its junction with the posterior communicating artery and this segment also called post communicating part of PCA or peri mesencephalic segment ${ }^{7}$. 


\section{Anatomical Measurements Of Cerebral Arteries Using Digital Subtraction Angiography}

\section{Statistical study:}

SPSS software version 20 (Armonk, NY: IBM Corp.) was used for statistical analysis of the results of this study. The data were presented as arithmetic means \pm SD (standard deviation). Statistical differences between different groups were performed using unpaired t-est. When Probability (P) value $<0.05$ statistical significance was decided.

\section{RESULTS:}

In the current study the ACA was measured in 2 segments. Segment-1 (A1) was shown in figures $(1,2)$. The total length of segment 1 (A1) varied between $12.93 \mathrm{~mm}$ and $19.77 \mathrm{~mm}$ on the right side and between $13.94 \mathrm{~mm}$ and $18.56 \mathrm{~mm}$ on the left side while its diameter varied between $2.29 \mathrm{~mm}$ and $2.93 \mathrm{~mm}$ on the right side and between $2.35 \mathrm{~mm}$ and $3.08 \mathrm{~mm}$ on the left side.

On the other hand, segment-2 (A2) was shown in figures $(1 \& 3)$. The total length of segment-2 (A2) varied between $34.99 \mathrm{~mm}$ and $41.65 \mathrm{~mm}$ on the right side and between $35.09 \mathrm{~mm}$ and $41.97 \mathrm{~mm}$ on the left side while its diameter varied between $1.72 \mathrm{~mm}$ and $2.96 \mathrm{~mm}$ on the right side and between $1.64 \mathrm{~mm}$ and $2.9 \mathrm{~mm}$ on the left side.

The first segment of MCA (M1) was measured in figures $(1 \& 4)$ and the total length of this segment varied between 38.96 $\mathrm{mm}$ and $46.1 \mathrm{~mm}$ on the right side and between $42.13 \mathrm{~mm}$ and $49.61 \mathrm{~mm}$ on the left side while its diameter varied between 2.56 $\mathrm{mm}$ and $3.68 \mathrm{~mm}$ on the right side and between $2.54 \mathrm{~mm}$ and $3.66 \mathrm{~mm}$ on the left side.
The PCA was measured in 2 segments. Segment-1 (P1) was shown in figures (5\&6). The total length of segment-1 (P1) varied between $4.69 \mathrm{~mm}$ and $14.67 \mathrm{~mm}$ on the right side and between $4.77 \mathrm{~mm}$ and $14.79 \mathrm{~mm}$ on the left side while its diameter varied between $1.67 \mathrm{~mm}$ and $2.49 \mathrm{~mm}$ on the right side and between $1.68 \mathrm{~mm}$ and $2.5 \mathrm{~mm}$ on the left side. On the other hand, segment-2 (P2) was measured as shown in figures (5\&7). The total length of segment-2 (P2) varied between $32.23 \mathrm{~mm}$ and $45.39 \mathrm{~mm}$ on the right side and between $32.53 \mathrm{~mm}$ and $45.57 \mathrm{~mm}$ on the left side while its diameter varied between $1.66 \mathrm{~mm}$ and $2.48 \mathrm{~mm}$ on the right side and between $1.67 \mathrm{~mm}$ and 2.49 mm on the left side.

There is no statistically significant relationship between diameters of cerebral arteries at different segments and sex of studied subjects. Also, there is no statistical significant relationship between lengths of cerebral arteries at different segments and sex of studied subjects.

Regarding to the age of studied subjects, there was statistical significant difference between the diameters of cerebral arteries in the 2 studied age groups at different segments and the diameters of these arteries were decreased by advancing in age as shown in table (1).

Regarding to the age of studied subjects, there was statistical significant difference between lengths of cerebral arteries in the 2 studied age groups at different segments and the lengths of these arteries were increased by advancing in age as shown in table (2) . 
Nancy Husseiny Hassan, et al.,

Table (1): Association between diameters of cerebral arteries and age of studied subjects.

\begin{tabular}{|c|c|c|c|c|c|c|}
\hline \multirow[t]{2}{*}{ variable } & \multicolumn{2}{|c|}{ 20-39 years } & \multicolumn{2}{|c|}{$40-60$ years } & \multirow[t]{2}{*}{$\mathrm{T}$ test } & \multirow[t]{2}{*}{$\mathrm{P}$} \\
\hline & mean & $\mathrm{SD}$ & mean & $\mathrm{SD}$ & & \\
\hline RT A1 & \multicolumn{2}{|c|}{$2.75 \pm 0.30$} & \multicolumn{2}{|c|}{$2.32 \pm 0.14$} & 5.552 & 0.0001 \\
\hline LT A1 & \multicolumn{2}{|c|}{$2.88 \pm 0.36$} & \multicolumn{2}{|c|}{$2.42 \pm 0.15$} & 5.140 & 0.0001 \\
\hline RTA2 & \multicolumn{2}{|c|}{$2.59 \pm 0.62$} & \multicolumn{2}{|c|}{$1.90 \pm 0.31$} & 4.343 & 0.0001 \\
\hline LT A2 & \multicolumn{2}{|c|}{$2.52 \pm 0.63$} & \multicolumn{2}{|c|}{$1.84 \pm 0.33$} & 4.216 & 0.0001 \\
\hline RT M1 & \multicolumn{2}{|c|}{$3.31 \pm 0.56$} & \multicolumn{2}{|c|}{$2.79 \pm 0.40$} & 3.486 & 0.0001 \\
\hline LT M1 & \multicolumn{2}{|c|}{$3.33 \pm 0.56$} & \multicolumn{2}{|c|}{$2.69 \pm 0.23$} & 4.605 & 0.0001 \\
\hline RT P1 & \multicolumn{2}{|c|}{$2.26 \pm 0.40$} & \multicolumn{2}{|c|}{$1.76 \pm 0.16$} & 4.911 & 0.0001 \\
\hline LT P1 & \multicolumn{2}{|c|}{$2.27 \pm 0.40$} & \multicolumn{2}{|c|}{$1.77 \pm 0.16$} & 5.0005 & 0.0001 \\
\hline RT P2 & \multicolumn{2}{|c|}{$2.25 \pm 0.40$} & \multicolumn{2}{|c|}{$1.76 \pm 0.16$} & 4.910 & 0.0001 \\
\hline LT P2 & \multicolumn{2}{|c|}{$2.26 \pm 0.40$} & \multicolumn{2}{|c|}{$1.76 \pm 0.16$} & 4.951 & 0.0001 \\
\hline
\end{tabular}

$\mathrm{SD}=$ standard deviation. $\quad \mathrm{P}$ (Probability value) $<0.05$.

Table (2): Association between lengths of cerebral arteries and age of studied subjects.

\begin{tabular}{|c|c|c|c|c|c|c|}
\hline \multirow[t]{2}{*}{ variable } & \multicolumn{2}{|c|}{ 20-39 years } & \multicolumn{2}{|c|}{$40-60$ years } & \multirow[t]{2}{*}{ T test } & \multirow[t]{2}{*}{$\mathrm{P}$} \\
\hline & mean & SD & mean & SD & & \\
\hline RT A1 & \multicolumn{2}{|c|}{$15.11 \pm 4.65$} & \multicolumn{2}{|c|}{$17.11 \pm 2.03$} & 2.113 & 0.0398 \\
\hline LT A1 & \multicolumn{2}{|c|}{$14.35 \pm 1.40$} & \multicolumn{2}{|c|}{$17.31 \pm 2.01$} & 5.507 & 0.0001 \\
\hline RTA2 & \multicolumn{2}{|c|}{$35.57 \pm 1.26$} & \multicolumn{2}{|c|}{$39.87 \pm 3.13$} & 5.547 & 0.0001 \\
\hline LT A2 & \multicolumn{2}{|c|}{$35.79 \pm 1.37$} & \multicolumn{2}{|c|}{$40.07 \pm 3.30$} & 5.234 & 0.0001 \\
\hline RT M1 & \multicolumn{2}{|c|}{$39.51 \pm 1.48$} & \multicolumn{2}{|c|}{$44.23 \pm 3.27$} & 5.762 & 0.0001 \\
\hline LT M1 & \multicolumn{2}{|c|}{$42.60 \pm 2.75$} & \multicolumn{2}{|c|}{$47.71 \pm 2.86$} & 6.143 & 0.0001 \\
\hline RT P1 & \multicolumn{2}{|c|}{$6.27 \pm 1.66$} & \multicolumn{2}{|c|}{$11.60 \pm 5.21$} & 4.205 & 0.0001 \\
\hline LT P1 & \multicolumn{2}{|c|}{$6.37 \pm 1.62$} & \multicolumn{2}{|c|}{$11.70 \pm 5.24$} & 4.187 & 0.0001 \\
\hline RT P2 & \multicolumn{2}{|c|}{$33.73 \pm 4.08$} & \multicolumn{2}{|c|}{$41.66 \pm 5.98$} & 5.002 & 0.0001 \\
\hline LT P2 & \multicolumn{2}{|c|}{$33.94 \pm 4.02$} & \multicolumn{2}{|c|}{$41.93 \pm 5.87$} & 5.127 & 0.0001 \\
\hline
\end{tabular}

$\mathrm{SD}=$ standard deviation.

The difference between the diameters of cerebral arteries on the right and left sides is statistically non-significant. Also, the difference between the lengths of cerebral arteries on the right and left sides is statistically non-significant in all segments

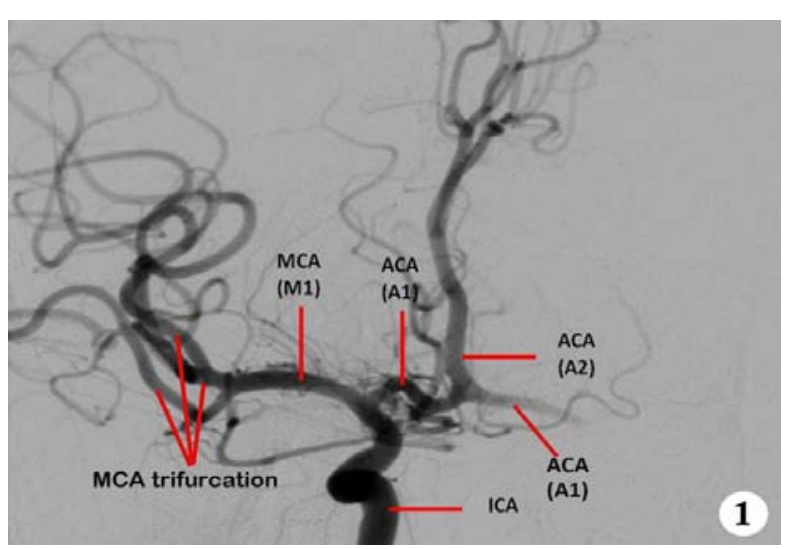

Fig. 1: DSA showing the carotid system . $\mathrm{ICA}=$ Internal carotid artery, ACA (A1) = Segment 1 of anterior cerebral artery, ACA (A2) =segment 2 of anterior cerebral artery and MCA $(\mathrm{M} 1)=$ segment 1 of middle cerebral artery. Trifurcation of MCA was observed. Also in this case, ACA (A2) called classical azygos anterior cerebral artery . except that of M1 segment which is statistically significant $(\mathrm{P}$. value $=0.0001)$. Fusion of both anterior cerebral arteries resulted in the formation of classical azygos anterior cerebral artery that was seen in one case $(2 \%)$ as shown in figure (1) .

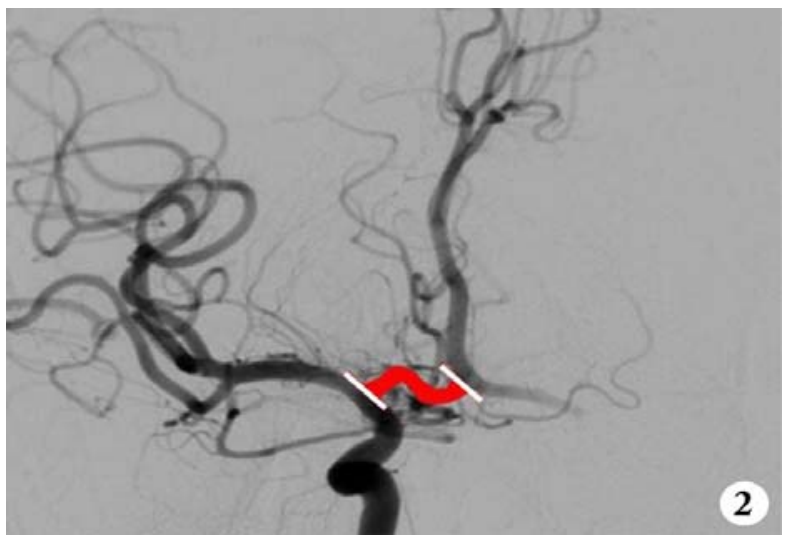

Fig. 2: DSA showing the measurement of length of segment(A1) of ACA . 


\section{Anatomical Measurements Of Cerebral Arteries Using Digital Subtraction Angiography}

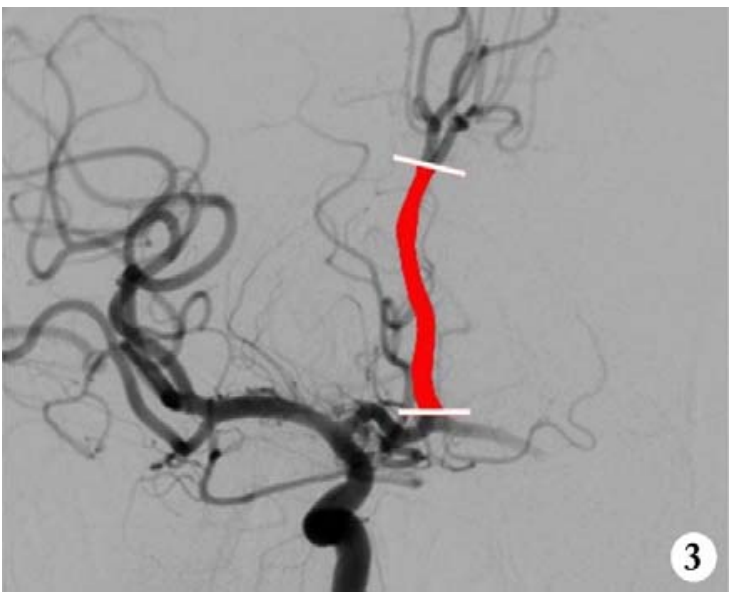

Fig. 3 : DSA showing the measurement of length of segment (A2) of ACA .

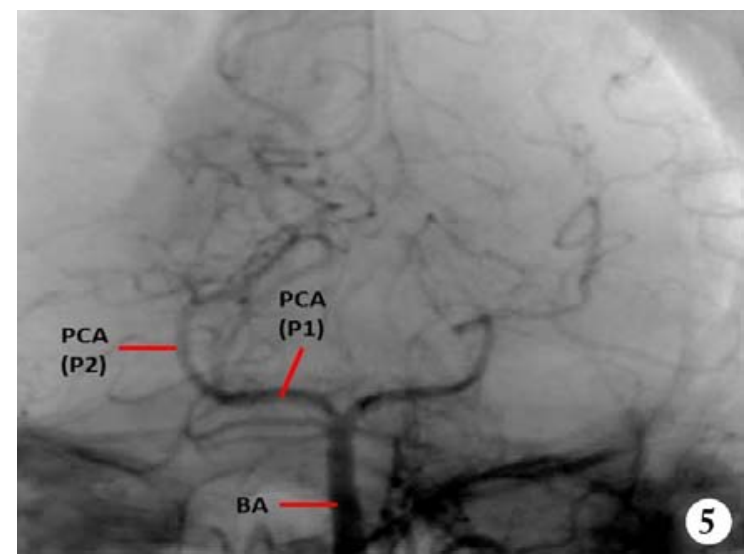

Fig. 5: DSA showing the vertebro-basilar system, BA= Basilar Artery, PCA (P1) = Segment 1 of posterior cerebral artery, PCA $(\mathrm{P} 2)=$ segment 2 of posterior cerebral artery.

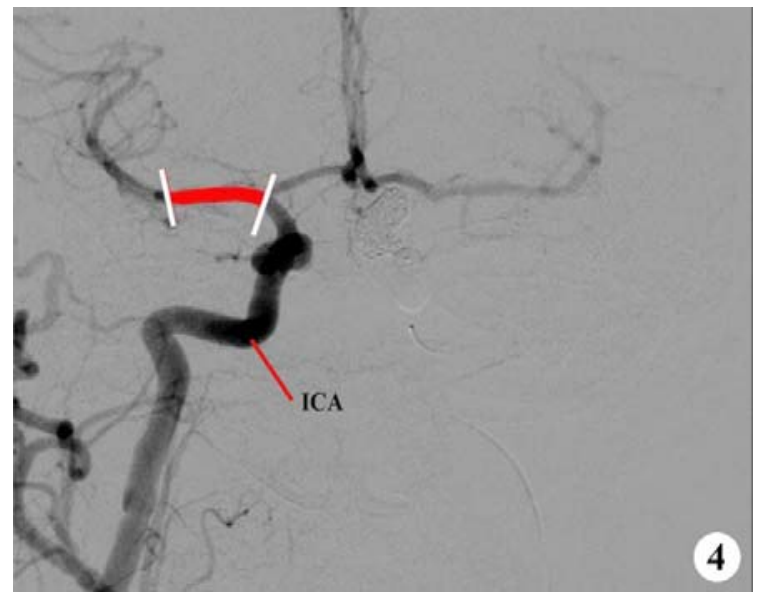

Fig. 4: DSA showing the measurement of length of segment (M1) of MCA \& ICA=Internal carotid artery .

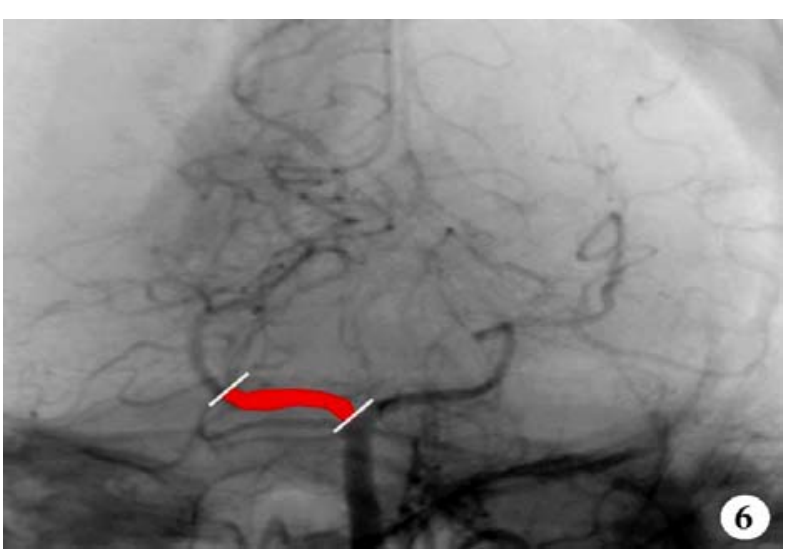

Fig. 6: DSA showing the measurement of length of segment (P1) of PCA .

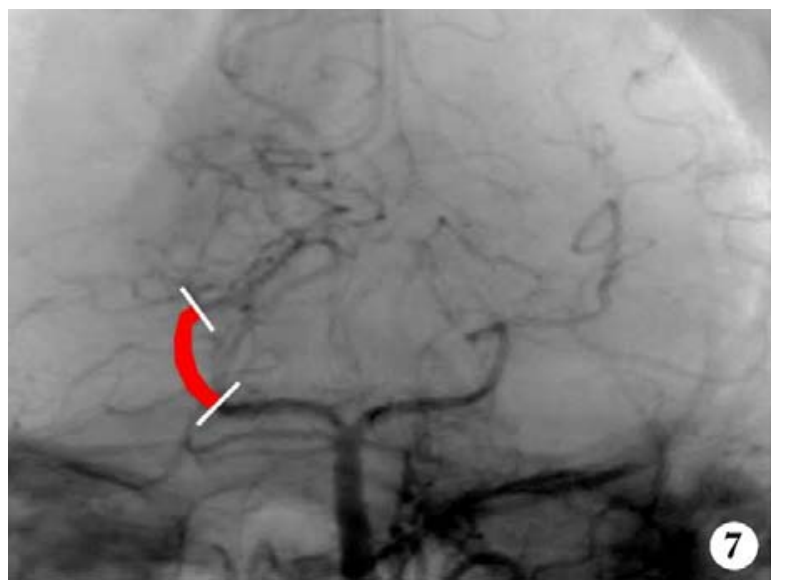

Fig. 7: DSA showing the measurement of length of segment (P2) of PCA . 


\section{DISCUSSION:}

The morphometry of the cerebral arteries had been studied in different populations by using different methods of measurements and the results varied in different races $^{8}$. The lengths of the segments of the vessels sharing in the circle of Willis have important value for the blood flow inside them. The non-linearity of the blood flow of the vessel segments is caused by their tortuosity and small lengths relative to their diameters ${ }^{8}$. The large asymmetries in the volume flow between the right and left sides is not caused by vascular diseases only but may be caused also by the variations in the anatomy of the circle of Willis ${ }^{9}$. The anatomical measurements of the ACA have important value to plan the endovascular procedures and design devices such as angiographic micro-catheters ${ }^{10}$. Uchino et al. ${ }^{11}$ added that knowledge of the variations of the cerebral arteries has a great value in the interpretations of cranial angiograms. In the present study, the use of DSA provided detailed and clear measurements to the lengths and diameters of all three cerebral arteries (anterior middle, and posterior

Table (3): The length of anterior cerebral artery (A1 segment) in various studies.

\begin{tabular}{|c|c|c|}
\hline \multirow{2}{*}{ Study } & \multicolumn{2}{|c|}{$\begin{array}{c}\text { Mean length of anterior cerebral artery }(\mathrm{mm}) \\
\pm \mathrm{SD}\end{array}$} \\
\hline & On the right side & On the left side \\
\hline Orlandini et al. ${ }^{16}$ & $14.1 \pm 2.7$ & $13.6 \pm 2.8$ \\
\hline Mandiola et al. ${ }^{17}$ & $12.86 \pm 1.58$ & $12.6 \pm 1.96$ \\
\hline Krishnamurthy et al. ${ }^{18}$ & $14.49 \pm 0.28$ & $14.22 \pm 0.22$ \\
\hline Aggarwal et al. ${ }^{4}$ & $15.78 \pm 3.71$ & $17.37 \pm 4.84$ \\
\hline The present study & $16.11 \pm 3.4$ & $15.83 \pm 2.31$ \\
\hline
\end{tabular}

$\mathrm{SD}=$ standard deviation

In the present study, the mean diameter of A2 segments was $2.24 \pm 0.62 \mathrm{~mm}$ on the right side and decreased on the left side to be $2.18 \pm$ $0.63 \mathrm{~mm}$ while its mean length was $37.72 \pm 3.33$ $\mathrm{mm}$ on the right side and increased on the left side to be $37.93 \pm 3.44 \mathrm{~mm}$. Gunnal et al. ${ }^{5}$ postulated that the mean diameter and length of (A2) was $2.5 \mathrm{~mm}$ and $42.1 \mathrm{~mm}$ respectively.
Also , the authors added that the classical azygos anterior cerebral artery was seen in the anterior median cerebral fissure of brain and supplies both cerebral hemispheres by its branches and this type of ACA was seen in 3 cases $(2.7 \%)$, moreover this variation was noticed in the present study in one case only (2\%) and was documented in the results. In cerebral arteries). Measurement of the dimensions of cerebral arteries by using angiograms is an accurate method ${ }^{12 \& 13}$. On the other hand, some studies used traditional cadaveric methods in measurement the dimensions of cerebral arteries ${ }^{5-7 \& 14}$. Aggarwal et al. $^{4}$ postulated that the knowledge of normal dimensions of ACA has an important value to the surgeons for assessment of the feasibility of shunt operations. Regarding to the ACA in the present study, the mean diameter of A1 segments was $2.53 \pm 0.33 \mathrm{~mm}$ on the right side and increased on the left side to be 2.65 $\pm 0.37 \mathrm{~mm}$ while its mean length was 16.11 $\pm 3.4 \mathrm{~mm}$ on the right side and decreased on the left side to be $15.83 \pm 2.31 \mathrm{~mm}$. Gunnal et al. ${ }^{5}$ observed that the mean diameter and length of the A1 of the anterior cerebral artery (A1) was $3.2 \mathrm{~mm}$ and $15.7 \mathrm{~mm}$. respectively. Also by using public domain software, Ansari et al. ${ }^{15}$ added that the length of the A1 segment was $12.5 \pm 2.2$ $\mathrm{mm}$.

The mean length of ACA (A1 segment) in the present study was compared with other available studies as in (table 3 ). 


\section{Anatomical Measurements Of Cerebral Arteries Using Digital Subtraction Angiography}

regard to the diameter and length of MCA in the present study, the mean diameter of M1 was $3.05 \pm 0.56 \mathrm{~mm}$ on the right side and decreased on the left side to be $3.01 \pm 0.56 \mathrm{~mm}$ while its mean length was $41.87 \pm 3.57 \mathrm{~mm}$ on the right side and increased on the left side to be $45.15 \pm$ $3.74 \mathrm{~mm}$. The results of a study by Cieślicki ${ }^{19}$ were in line with the present study and he stated that the M1 average length on the left side was $51 \mathrm{~mm}$ while its diameter was $3 \mathrm{~mm}$, and on the right side was $42 \mathrm{~mm} \mathrm{\& 3} \mathrm{mm}$ for length and diameter respectively. On the other hand many authors were in disagreement with this study, Pai et al. ${ }^{6}$ recorded that the length of MCA ranged from 12 to $28 \mathrm{~mm}$ (its mean was $20 \mathrm{~mm}$ ) and the outer diameter of the main trunk of MCA ranged from 2.5 to $4 \mathrm{~mm}$ ( its mean of $3.35 \mathrm{~mm}$ ). In this study, the mean diameter of P1 segments was $2.01 \pm 0.41 \mathrm{~mm}$ on the right side and increased on the left side to be $2.02 \pm$ $0.41 \mathrm{~mm}$ while its mean length was $8.93 \pm 4.99$ $\mathrm{mm}$ on the right side and increased on the left side to be $9.03 \pm 5.01 \mathrm{~mm}$. These results were in disagreement with Párraga et al. ${ }^{7}$ who found that the average length of P1 segment was $7.7 \mathrm{~mm}$. In the present study, the mean diameter of P2 segments was $2.0 \pm 0.41 \mathrm{~mm}$ on the right side and increased on the left side to be $2.01 \pm$ $0.41 \mathrm{~mm}$ while its mean length was $37.69 \pm 6.58$ $\mathrm{mm}$ on the right side and increased on the left side to be $37.93 \pm 6.52 \mathrm{~mm}$. Párraga et al. ${ }^{7}$ observed that $\mathrm{P} 2$ segment was divided into an anterior $(\mathrm{P} 2 \mathrm{~A})$ and posterior $(\mathrm{P} 2 \mathrm{P})$ segments. The P2A segment measured between the posterior communicating artery till the most lateral side of the cerebral peduncle, with an average length was $23.6 \mathrm{~mm}$ while its average diameter was $1.7 \mathrm{~mm}$ and the $\mathrm{P} 2 \mathrm{P}$ segment extends from the end of $\mathrm{P} 2 \mathrm{~A}$ till the posterior edge of the lateral surface of the midbrain, with an average length was $16.4 \mathrm{~mm}$ while its average diameter was $1.4 \mathrm{~mm}$.

In conclusion application of the present study that was carried out to measure diameters and lengths of main cerebral arteries (ACA, PCA and MCA) on both sides, can establish standards for anatomical Egyptian measurements of these arteries by using DSA .

Acknowledgements: Many thanks to the subjects involved in this study and clinicians staff of Interventional Radiology Unit of
Diagnostic Radiology Department, Faculty of medicine, Zagazig University.

Conflicts of interest: No conflicts of interest.

\section{REFERENCES}

1. Vrselja,Z.; Brkic,H.; Mrdenovic, S.; Radic,R. and Curic, G. (2014) : Function of circle of Willis . Journal of Cerebral Blood Flow \& Metabolism 34(4):578-584.

2. Parmar, H ; Sitoh, YY and Hui, F. (2005): Normal variants of the intracranial circulation demonstrated by MR angiography at 3T. Eur $J$ Radiol. 56(2):220-228.

3. Weinstein, PR (1983): Digital subtraction angiography . Clin Neurosurg. 31:90-106.

4. Aggarwal, N.; Paul,M.M.; Mukherjee,M.; Toppo, J.N. ; Kaur,M. and Goel,G. (2012): Length of the Anterior Cerebral Artery (ACA) on MRI Angiograms. Journal of Clinical and Diagnostic Research. 6(5): 764-766.

5. Gunnal,S.A. ;Wabale,R.N. and Farooqui,M.S. (2013): Variations of anterior cerebral artery in human cadavers . Neurology Asia 2013; 18(3): 249 - 259.

6. Pai, $S B$;Varma, $R G$ and Kulkarni, $R N$ (2005): Microsurgical anatomy of the middle cerebral artery. Neurol India 53(2) :186-190.

7. Párraga, $R G$; Ribas, $G C$; Andrade, $S E$ and de Oliveira, E. (2011): Microsurgical anatomy of the Posterior Cerebral Artery in three-dimensional images. World Neurosurg. 75 (2): 233-257.

8. Cieslicki, K. and Ciesla, D. (2005): Investigations of flow and pressure distributions in physical model of the circle of Willis. J Biomech. 38(11):2302-2310.

9. Hendrikse, $J$; van Raamt, AF ; van der Graaf, $Y$; Mali, WP and van der Grond, $J$ (2005): Distribution of cerebral blood flow in the circle of Willis. Radiology. 235(1):184-189. 


\section{Nancy Husseiny Hassan, et al.,}

10. Stefani, MA; Schneider, FL; Marrone, $A C$; Severino, $A G$ and Wallace, $M C$ (2000): Anatomic variations of anterior cerebral artery cortical branches. Clin Anat. 13(4):231-236.

11. Uchino, A.; Nomiyama, K.; Takase, Y. and Kudo, S. (2006) : Anterior cerebral artery variations detected by MR angiography. Neuroradiology. 48(9): 647-652.

12. Ferguson SD; Rosen DS; Bardo, D ; Macdonald RL.(2010): Arterial diameters on catheter and computed tomographic angiography. World Neurosurgery 73 (3): 165-173.

13. Voljevica, A.; Talovic, E.; Pepic,E. and Kapic, AP. (2013): Morphometric Analysis of Willis circle Arteries. Arch Pharma Pract, 4(2): 77-82.

14. Pai, SB; Kulkarni, $R N$ and Varma, $R G$. (2005): Microsurgical anatomy of the anterior cerebral artery- anterior communicating artery complex: An Indian study. Neurology Asia $10: 21-28$.

15. Ansari $S$, Dadmehr $M$, Eftekhar $B$ , McConnell DJ, Ganji $S$, Azari $H$, Kamali-Ardakani S, Hoh BL. and Mocco J. (2011): A simple technique for morphological measurement of cerebral arterial circle variations using public domain software (Osiris). Anat Cell Biol. 44 (4): 324-330.

16. Orlandini, GE; Ruggiero, C; Orlandini, SZ and Gulisano, $M$ (1985): Blood vessel size of circulus arteriosus cerebri (circle of Willis): a statistical research on 100 human subjects. Acta Anat.(Basel) 123(1): 72-76.

17. Mandiola, E; Alarcon, E; Onate, JC ; Sanhueza, P ; Del Sol, $M$ and Olave, E. (2007): Biometrical aspects of the anterior cerebral artery in its proximal segment (A1) and internal carotid artery. Int J Morphol. 25(4): 915-918.

18. Krishnamurthy A, Nayak SR , Bagoji IB, D'Costa S, Pai MM, Jiji PJ, Kumar CG and Rai R. (2010): Morphometry of Al segment of anterior cerebral artery and its clinical importance. Clinica Terapeutica 161(3) :231-234.

19. Cieślicki, K. (2004): Experimental and numerical modelling of flow in the human cerebral arteries. Journal of Medical Informatics \&Technologies 7, ISSN 16426037. 


$$
\begin{aligned}
& \text { القياسات التشريحية للشرايين المخية باستخدام تصوير الأوعية بالطرح الرقمى } \\
& \text { ناتسي حسيني حسن - متولي عبد الباري منصور - امل الشحات ابراهيم - ابراهيم حسن ابراهيم } \\
& \text { قسم التشريح و الأجنه ـ كلية الطب البشري - جامعة الزقازيق ـ محافظه الثرقيه ـ جمهوريه مصر العربيه }
\end{aligned}
$$

المقدمه: ان معرفه القياسات التشريحيه للشرايين المخيه لها قيمه عظيمه لفهم الاضطرابات العصبيه.

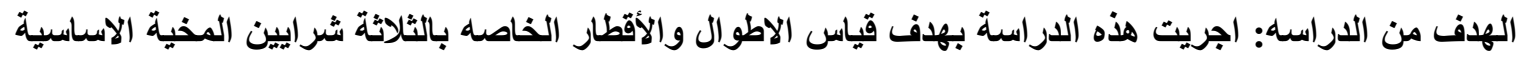

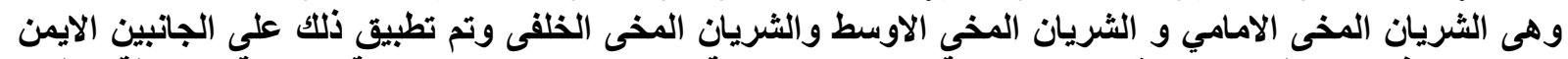

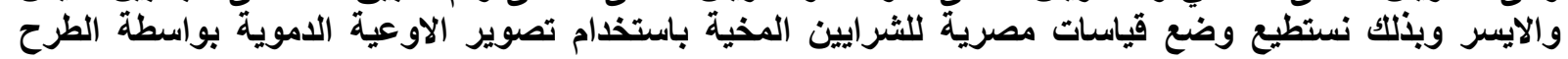
الرقمى.

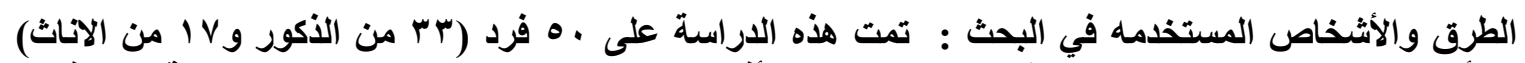

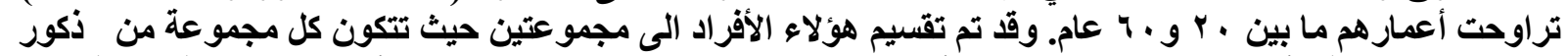

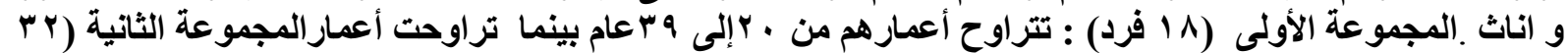

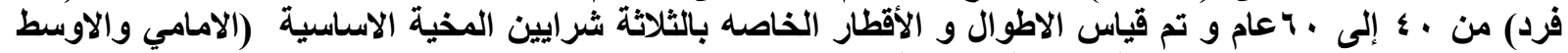

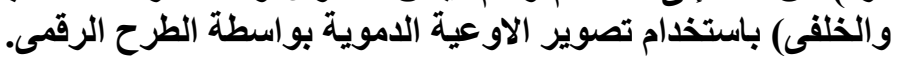

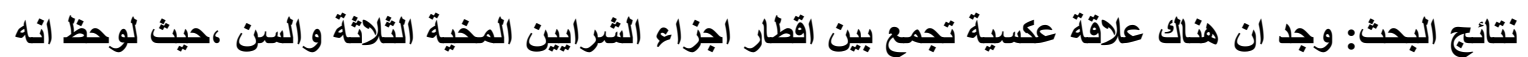

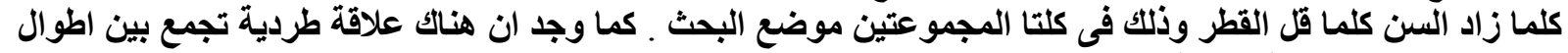

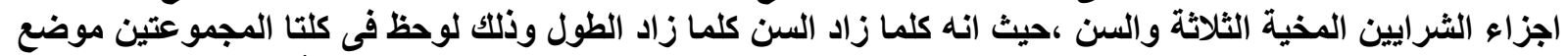

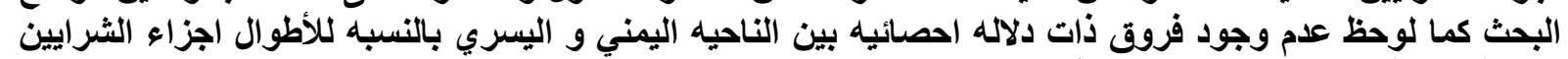

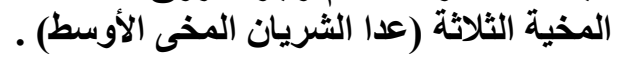

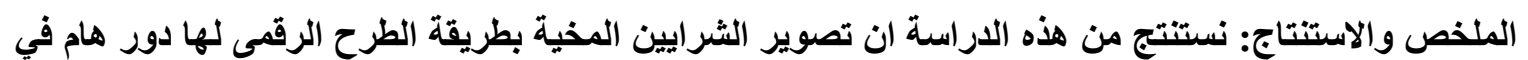

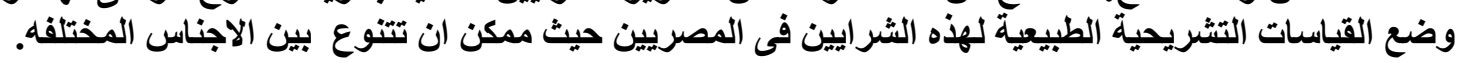

